\title{
It's not what you put in that is important, it's what you take out
}

\author{
Christopher M. Feindel, MD, MSc, BEng, FRCS(C)
}

\author{
From the Antonio \& Helga DeGasperis Chair in Clinical Outcomes Research in Cardiac Surgery, Department of \\ Surgery, University of Toronto, Toronto, Ontario, Canada. \\ Disclosures: Author has nothing to disclose with regard to commercial support. \\ Received for publication Dec 30, 2015; accepted for publication Jan 2, 2016; available ahead of print Feb 6, 2016 \\ Address for reprints: Christopher M. Feindel, MD, MSc, BEng, FRCS(C), Peter Munk Cardiac Centre, University \\ Health Network, 200 Elizabeth St, Room 4N-480, Toronto, Ontario M5G 2C4, Canada (E-mail: Chris. \\ Feindel@uhn.ca; http://www.petermunkcardiaccentre.ca). \\ J Thorac Cardiovasc Surg 2016;151:1249-50 \\ $0022-5223 / \$ 36.00$ \\ Copyright (C) 2016 by The American Association for Thoracic Surgery \\ http://dx.doi.org/10.1016/j.jtcvs.2016.01.002
}

In this issue of the Journal, Kim and colleagues ${ }^{1}$ present an analysis of 304 observed cases of acute infective endocarditis (IE) involving the aortic valve treated surgically from 2 well-known academic institutions (Massachusetts General Hospital and Brigham and Women's Hospital) during a 12-year period. This is one of the largest series of acute IE ever reviewed. After evaluating short- and long-term outcomes, Kim and colleagues ${ }^{1}$ came to 3 conclusions: (1) There was no benefit associated with using homografts with regard to resistance to reinfection. (2) Prosthesis choice should be based on technical and patient factors. (3) The lack of availability of homografts should not impede the choice of surgical intervention.

The underlying theme of the article of Kim and colleagues ${ }^{1}$ is to challenge the surgical dogma that autologous or allogenic tissue is preferable to synthetic material in an infected field. This article delivers an important message, although not all surgeons will agree with the statistical approach taken by $\mathrm{Kim}$ and colleagues ${ }^{1}$; more on that later. Cardiac surgeons with experience in treating IE understand that the main goal of surgery is to remove all infected material, as if it were a cancer, an approach that is fully supported by $\mathrm{Kim}$ and colleagues ${ }^{1}$ as well as by others. ${ }^{2,3}$ "Radical resection," however, may lead to significant intraoperative challenges when it comes to reconstructing the heart, and it is during this phase of the surgery when intraoperative technical problems are most likely to occur. Knowing this, surgeons in the past may have been conservative when débriding surrounding infected tissue in an attempt to avoid some of the risks associated with major reconstructive procedures. In such settings, homografts were favored because they were thought to fare better with regard to the risk of reinfection, and this is likely the origin of the "dogma" that recommended using homografts in preference to other artificial prosthesis in acute IE. More recent experience, however, has suggested that if all infected material is removed, then reinfection rates are probably not related to the type of prosthetic valve used in the reconstructive phase. In support of this more contemporary opinion, Kim and

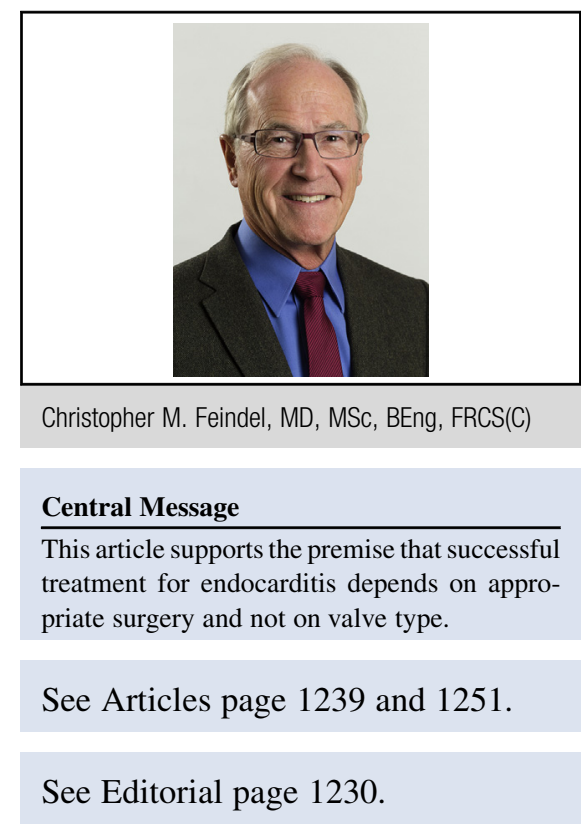

colleagues ${ }^{1}$ state that their "current study adds to the literature by virtue of rigorous risk adjustment methodology to overcome selection bias in our treatment cohort as well as relatively heterogeneous attitudes and preference among a large group of surgeons involved.'

The series of $\mathrm{Kim}$ and colleagues ${ }^{1}$ indeed provides further support that the type of prosthesis used in IE probably does not affect long-term outcomes or reinfection rates after successful surgery. As in any observational study, however, numerous confounding factors were likely present. This is a heterogeneous group of patients treated during a 12-year period by more than 20 different surgeons. Patients with acute IE are unique in that they present with a wide range of pathology, pathology that often requires a uniquely tailored operation, as opposed to say an aortocoronary bypass or an uncomplicated valve replacement. In some cases, only leaflet infection is present, easily corrected with an isolated valve replacement. In other cases, there may be partial damage to the aortic annulus, requiring local patch repair followed by valve replacement. In more extreme cases, the entire aortic root as well as the surrounding tissue may be infected, necessitating a wide resection with subsequent reconstruction using multiple patches and a valved conduit. These various scenarios can test the mettle of even the most experienced surgeons who would agree that patient factors as well as their own abilities will greatly influence the intraoperative decisions, including the choice of valve prosthesis. So on this basis of this study, if the entire aortic root requires replacement, should a surgeon 
select a homograft, or is it reasonable to use a xenograft or mechanical valve conduit?

In this series Kim and colleagues ${ }^{1}$ have used the propensity score method with inverse probability of treatment weighting in an attempt to remove the effects of treatment-selection bias. In their analysis treatment is considered to represent the use of a homograft valve, whereas nontreatment is treatment with either a xenograft or mechanical valve rather than with a homograft valve. Kim and colleagues ${ }^{1}$ considered a large number of covariates, including bacteriologic pathogen type, prosthetic valve IE, heart failure class, presence of an abscess, and others, and in their opinion this matching created 2 balanced cohorts, one in which homografts were used and the other in which they were not used (ie, in which xenografts and mechanical valves were used). A crucial assumption for effective use of the propensity score is that all baseline variables known to affect treatment assignment and outcomes have been measured. Given the numerous factors in treating patients with acute and in many cases complex IE referred to previously, most surgeons would have difficulty accepting that all "cofounders" have been accounted for in this model. It is even doubtful that one could ever account for all the confounders in any heterogeneous group of patients with complex IE. Kim and colleagues ${ }^{1}$ clearly acknowledge these limitations of their retrospective observational study. The reader is referred to several excellent articles on the use of different propensity score methods in analyzing observational data. ${ }^{4-7}$

It would have been very instructional in this series to examine the 115 of the 304 patients who underwent root replacement, because they represent a separate and somewhat more homogenous group that likely required similar complex decisions to be made by the operating surgeon. In fact Kim and colleagues ${ }^{1}$ refer to a study by Jasser and associates $^{8}$ from the University of Pennsylvania in which 134 patients with complex IE were treated by root replacement with a mechanical conduit $(\mathrm{n}=43)$, a xenograft conduit $(\mathrm{n}=55)$, or a homograft conduit $(\mathrm{n}=36)$. The University of Pennsylvania group reported similar operative mortalities $(22 \%)$ and similar rates of late readmission, reinfection, and reoperation for all 3 conduit types, which further supports the contention that prosthesis type does not appear to affect long-term outcomes. Finally, Kim and colleagues $^{1}$ freely admit that the lack of follow-up on valve-related complications in almost $25 \%$ of their patients is a limitation of their study.

Notwithstanding the limitations of their analysis, Kim and colleagues ${ }^{1}$ have concluded that "no significant benefit to the use of homografts was demonstrable with regard to resistance to reinfection in the setting of IE." Furthermore, "the choice among prosthetic options should be based on technical and patient specific factors." These are reasonable conclusions, and clearly this article contributes important additional information to the surgical management of IE that will help guide surgeons, especially when it comes to prosthesis of choice. It is up to the reader to decide whether this report finally puts to rest the "dogma" that homografts should preferentially be used in the setting of IE.

\section{References}

1. Kim JB, Ejiofor JI, Yammine M, Camuso JM, Walsh C, Ando M, et al. Are homografts superior to conventional prosthetic valves in the setting of infective endocarditis? J Thorac Cardiovasc Surg. 2016;151:1239-48.e2.

2. David TE, Gavra G, Feindel CM, Regesta T, Armstrong S, Maganti MD. Surgical treatment of active infective endocarditis: a continued challenge. J Thorac Cardiovasc Surg. 2007;133:144-9.

3. Feindel CM. 50th Anniversary Landmark Commentary on David TE, Bos J, Christakis GT, Brofman PR, Wong D, Feindel CM. Heart Valve Operations in Patients With Active Infective Endocarditis. Ann Thorac Surg. 1990;49:701-5. Ann Thorac Surg. 2015;100:1531-3.

4. Austin PC. An introduction to propensity score methods for reducing the effects of the confounding in observational studies. Multivariate Behav Res. 2011;46: 399-424.

5. Austin PC. Propensity-score matching in the cardiovascular surgery literature from 2004 to 2006: a systematic review and suggestions for improvement. J Thorac Cardiovasc Surg. 2007;134:1128-35.

6. Curtis LH, Hammill BG, Eisenstein EL, Kramer JM, Anstrom KJ. Using inverse probability-weighted estimators in comparative effectiveness analyses with observational databases. Med Care. 2007;45(10 Suppl 2):S103-7.

7. D’Agostino RB Jr. Propensity scores in cardiovascular research. Circulation. 2007; 115:2340-3.

8. Jasser AS, Bavaria JE, Szeto WY, Moeller PJ, Maniaci J, Milewski RK, et al. Graft selection for aortic root replacement in complex endocarditis: does it matter? Ann Thorac Surg. 2012;93:480-7. 